\title{
Intelectuales y artistas por la Revolución: La Revista de Oriente, 1925-1926
}

Intellectuals and artists for the Revolution: Revista de Oriente, 1925-1926

Natalia Ávila*

Resumen: La Revolución Bolchevique impactó en el campo cultural argentino en los años '20. En este contexto, la Revista de Oriente fue un proyecto editorial llevado adelante por el abogado Arturo Orzábal Quintana y la Asociación de Amigos de Rusia durante 1925 y 1926. Esta revista cultural contó con la colaboración de intelectuales y artistas que buscaron en los lenguajes artísticos la forma de difundir la realidad de la Nueva Rusia.

Palabras clave: Revolución Rusa- Revistas culturales- Intelectuales- Arte

Abstract: The Bolshevik Revolution impacted in the Argentine cultural field in the '20. In this context, the "Revista de Oriente" was an editorial project directed by the lawyer Arturo Orzabal Quintana and the Asociación de Amigos de Rusia during 1925 and 1926. This cultural review had the collaboration of Latin-American and European intellectuals and artists who found in the artistic languages the way to spread the reality of the New Russia.

Keywords: Bolshevik Revolution- Cultural journals-Intellectuals-Art

\footnotetext{
* Argentina. Licenciada en Ciencias Sociales por la Universidad Nacional de Quilmes y becaria de la misma casa de estudios. Miembro del proyecto I+D "Universidad, vanguardias culturales y prácticas estéticas, académicas y políticas de los intelectuales en la argentina de las primeras décadas del siglo xx, 1920-1943”. natalia.p.avila@gmail.com. Se agradecen los comentarios anónimos que permitieron corregir la primera versión del presente trabajo.
} 


\section{Introducción}

En junio de 1925 salió a la calle en la ciudad de Buenos Aires el primer número de la Revista de Oriente. Esta publicación estuvo impulsada por el abogado Arturo Orzábal Quintana y la Asociación de Amigos de Rusia. Su principal objetivo fue el reconocimiento de la U.R.S.S por el gobierno argentino y la defensa del proletariado. En pos de esta meta, Revista de Oriente se caracterizó principalmente por la cantidad de imágenes en cada uno de sus números y la reproducción de textos literarios como de grabados e ilustraciones de las vanguardias argentinas y latinoamericanas.

Mientras que el itinerario intelectual de Orzábal Quintana, su director, permitió comprender las redes y propuestas de un proyecto editorial colectivo que buscó producir y divulgar un saber específico en las esferas cultural y política acerca de Rusia luego de la revolución. El análisis del universo de colaboradores de la revista muestra los vínculos en el campo intelectual a nivel nacional e internacional, la función que los editores buscaban en la reproducción de las obras de arte en sus páginas, la producción y difusión del saber acerca de la realidad soviética.

Entre los escasos estudios sobre esta publicación, se encuentra el realizado por Martín Bergel en su artículo Un caso de Orientalismo invertido. La Revista de Oriente (1925-1926) y los modelos de relevo de la civilización occidental (2006). El autor analizó la revista desde la historia de las ideas poniendo el eje en las significaciones de Oriente en los intelectuales de izquierda, aunque sin profundizar en sus estrategias de difusión en el campo cultural y político. Por otro lado, Horacio Tarcus en Revistas, intelectuales y formaciones culturales izquierdistas en la Argentina de los '20 (2004), realizó una reseña de los principales datos de Revista de Oriente, presentando algunos de sus colaboradores y temas de debate pero sin considerar las manifestaciones artísticas que la revista ofrecía a sus lectores, para diferenciarse de otras publicaciones que difundían la realidad soviética.

En los primeros años de la década del '20 José Ingenieros, Alfredo Palacios, Enrique del Valle Iberlucea entre otros, publicaron artículos y libros referidos a las transformaciones políticas y sociales ocurridas en Rusia a partir de la revolución. Sus escritos demuestran la preocupación de los intelectuales argentinos por evaluar este acontecimiento que consideraban una experiencia excepcional en la historia del nuevo siglo y potencialmente realizable en todo el mundo. El impacto del acontecimiento ruso repercutió profundamente en el campo cultural argentino y debe remarcarse que el principal vehículo elegido para su difusión por quienes lo tomaron como parte de su trabajo intelectual, fueron las publicaciones periódicas de izquierda. En este sentido, Revista de Oriente fue parte constitutiva de este conjunto de publicaciones destinadas a acercar al lector argentino la experiencia soviética. Impulsada por Arturo Orzábal Quintana como parte de su labor de analista de las relaciones internacionales, la singularidad de este proyecto editorial consistió en recurrir a los lenguajes del arte y la literatura para difundir la realidad soviética. 
La revista surgió a mediados de los años '20 momento en el que el campo cultural argentino experimentó su proceso de consolidación. En estos años, intelectuales y artistas buscaron la manera de expresar las rápidas transformaciones sociales y económicas que ocurrían en el país. Principalmente, el aumento poblacional y al mismo tiempo, de la tasa alfabetización generó el clima propicio para el desarrollo de un lector potencial, como señala Beatriz Sarlo ${ }^{1}$. También los hijos de inmigrantes durante esta década consolidaron su incorporación en el sistema de educación medio y en las universidades nacionales ${ }^{2}$

Aunque el mayor proceso de cambio educativo ocurrió en el sistema universitario como consecuencia de la Reforma Universitaria del año 1918. Los disturbios comenzaron en la Facultad de Medicina de la Universidad de Córdoba, donde los estudiantes se manifestaron contra de la supresión del internado. Sin embargo, las demandas eran más amplias: la actualización de los planes de estudio, la regularización de designación de los profesores y cambios en el gobierno universitario. Los reclamos se extendieron a las universidades de Buenos Aires y de La Plata. El impacto más importante fue la expansión del sistema universitario, la ampliación del acceso a las carreras y cátedras para los sectores medios, y la aparición del movimiento estudiantil como un nuevo actor político en la sociedad argentina ${ }^{3}$. Según Jorge Graciarena la Reforma expresó las demandas de la clase media de Argentina que luego de 1916, habiendo conquistado otros sectores de poder como el político, buscaron afirmar su movimiento ascensional también en las universidades.

Por otra parte, la recepción de una serie de escritores emergentes durante la Primera Guerra Mundial y la posguerra como José Ortega y Gasset, Eugenio D'ors, Henri Barbusse y Romain Rolland, Oswald Spengler ${ }^{4}$ repercutió en el campo cultural argentino. La influencia de estos autores se encontró en el discurso de intelectuales latinoamericanos. Por ejemplo, los argumentos de Spengler en La decadencia de Occidente que había tenido un gran impacto en Europa durante la posguerra, se reprodujeron y publicitaron en Latinoamérica. O de Ortega y Gasset, el filósofo español o de José Rodó y José Martí, quienes fueron los pioneros en instalar en el pensamiento de América Latina la idea de una identidad autóctona. Los cuestionamientos a la sociedad occidental durante y luego de la guerra aumentaron a medida que las consecuencias se intensificaron. Lo cual generó una inflexión cultural que se observó también en Latinoamérica incorporando al debate en revistas y conferencias interrogantes y criticas al sistema mundial capitalista.

En este período además surgieron nuevas tendencias estéticas y literarias. Hacia la década de 1920 estarán representadas en dos grupos diferenciados: Florida y Boedo. El primero de ellos se caracterizó por un estética ultraísta y por la influencia recibida de los grupos vanguardistas europeos como el surrealismo. Algunos de sus integrantes fueron

\footnotetext{
${ }_{1}^{1}$ Sarlo,Beatriz, Una modernidad periférica, Buenos Aires 1920-1930, (Buenos Aires; Nueva Vision, 2003)

2 Buchbinder, Pablo, Historia de las universidades en Argentina, (Buenos Aires: Sudamericana, 2009); Graciarena, Jorge, "Clases medias y movimiento estudiantil. El reformismo argentino", Revista mexicana de sociología, 3,1 (1971)

${ }^{3}$ Graciano, Osvaldo, Entre la torre de marfil y el compromiso político. Intelectuales de izquierda en argentina 1918-1955, (Bernal: Universidad Nacional de Quilmes, 2008)

${ }^{4}$ Baur, Sergio, "Itinerarios de la vanguardia argentina", Disarat hispánicas 1, 2014.
} 
Jorge Luis Borges, Evar Mendez y Oliverio Girondo. En cambio el grupo Boedo se enfocó en retratar la realidad porteña luego de los cambios en Buenos Aires a partir de su modernización, específicamente de los sectores más desfavorecidos.

Ambos grupos fueron consecuencia, en distinto grado, de los eventos políticos nacionales e internacionales. La primera experiencia democrática argentina incorporó las masas populares al espacio público. Como señala David Rock, la actividad electoral dejó de ser cuestión cooptación de votos mediante métodos fraudulentos como el soborno y evolucionó hasta convertirse en un problema de organización de masas. Una revolución paralela tuvo lugar en el arte de la propaganda política y surgió un nuevo estilo de periodismo popular. Por otro lado, la Gran Guerra Europea (1914-1918) dejó al Viejo Continente, modelo a seguir por los países de América Latina, destruido y con la civilización en "decadencia".

En 1917 ocurre la Revolución Bolchevique en Rusia, la cual fue interpretada por muchos intelectuales de izquierda argentinos como la esperanza de una nueva sociedad más justa e igualitaria que la capitalista. Su impacto fue gravitante en el mundo obrero de los años '20 y en las distintas corrientes ideológicas y políticas que actuaban en su seno, el espacio social y cultural de referencia de Revista de Oriente y en el que buscó captar parte de sus lectores. El crecimiento del movimiento obrero desde fines del siglo XIX con el auge de la inmigración y la organización de las actividades de exportación y la instalación del sector industrial en el área metropolitana, estuvo influenciado por las ideas anarquistas, socialistas y sindicalistas, logrando la movilización política de amplios sectores de trabajadores, la que se sostuvo en las primeras décadas del siglo XX. Como sostiene Hernán Camarero ${ }^{6}$, a partir de su fundación, el Partido Comunista se sumó a la disputa por la dirección ideológica del movimiento obrero, emprendiendo en la década del 20 una campaña de cooptación de afiliados en las fábricas y empresas de Buenos Aires, Rosario, Córdoba y Tucumán. Estos partidos y corrientes sindicales habían desarrollo sus propios dispositivos de prensa obrera, destinados a la capacitación sindical e ideológica de los trabajadores ${ }^{7}$.

Estos eventos más los cambios sociales tuvieron diferentes respuestas y posiciones por los grupos de intelectuales de las distintas tendencias ideológicas. No obstante la mayoría de ellos eligieron una forma de divulgarlas: la publicación periódica. Tanto los jóvenes reformistas con Sagitario, Valoraciones, Inicial, por mencionar solo algunas como el grupo Florida con Prisma, Proa y Martín Fierro y Boedo con Los Pensadores y luego de

\footnotetext{
${ }_{6}^{5}$ Rock, David, El radicalismo argentino. 1890-1930 (Buenos Aires: Amorrortu, 1992)

${ }^{6}$ Camarero Hernán, "La experiencia comunista en el mundo de los trabajadores, 1925-1935", Prismas. Revista de Historia Intelectual, 6, (2002), pp. 189-203.

${ }^{7}$ Camarero, Hernan, op. Cit. Además también se ha consultado Lobato, Mirta, La prensa obrera: Buenos Aires y Montevideo, 1890-1958, (Buenos Aires: Edhasa, 2009)
} 
la mitad de la década del '20 con Claridad $^{8}$, adoptaron este modo de presentar sus respectivas posiciones políticas y artísticas.

Esta última corriente, el grupo Boedo, fue una de las representantes del realismo argentino. María Teresa Gramuglio ${ }^{9}$ en su artículo de la colección dirigida por Noé Jitrik Historia crítica de la literatura argentina, indicó esta corriente literaria experimentó a partir de los años '20 una importante difusión en la cual la puesta en escena y crítica de la realidad tomó relevancia en el campo cultural.

La Revista de Oriente constituyó un proyecto que difundió tanto a los acontecimientos políticos nacionales e internacionales como también apeló a producciones y prácticas del campo artístico para impactar de un modo diferente en sus lectores.

Por lo tanto, el enfoque metodológico se centra principalmente en el concepto propuesto en el trabajo de Fernanda Beigel ${ }^{10}$ de revista cultural. También definiciones de Patricia Artundo ${ }^{11}$ a través de los cuales se especifican algunas de las funciones de este tipo de dispositivos de comunicación de la cultura impresa y por otro lado también se tomará la noción de revista literaria formulado por Verónica Delgado ${ }^{12}$ para comprender los elementos que completan cada uno de los números. Para el análisis de la revista se ha tomado el corpus de todos los números, procedido con la lectura de los artículos y el análisis de las imágenes que ilustran las portadas y las colaboraciones. A partir de ello teniendo en cuenta los prismas conceptuales mencionados, se ha intentado distinguir las estrategias de difusión del proyecto y la búsqueda y sostenimiento de lectores.

Mientras que el enfoque biográfico, en este caso siguiendo la propuesta de François Dosse, permitió comprender las particularidades y los vínculos que se desplegaron en Revista de Oriente. El autor francés sostiene que el estudio de los distintos momentos en la vida de un intelectual, no solo prestando atención a su producción o prácticas, complementa la comprensión de su actividad y distintos momentos de su trayectoria. Al mismo tiempo que ayuda a completar posibles «espacios vacíos» que no se hallan en las fuentes documentales. Por lo tanto, en este trabajo se consideró necesario realizar un breve pero esencial relato biográfico de Arturo Orzábal Quintana para luego comprender las redes y posturas ideológicas presentes en el proyecto de la revista.

\footnotetext{
${ }^{8}$ Respecto a la actividad pedagógica y publicitaria del grupo de Boedo y del grupo socialista Claridad se pueden consultar los trabajos de Florencia Ferreyra de Cassone. En ellos se encuentran análisis acerca del desarrollo de estas publicaciones y las colaboraciones y temas abordados.

${ }^{9}$ Gramuglio, María Teresa, "Introducción. El imperio realista" y "El realismo y sus destiempos en la literatura argentina", Historia crítica de la literatura argentina, vol 6, ed. Gramuglio María Teresa, dir. Jitrik Noel, (Buenos Aires: Emecé Editores, 2002)

${ }^{10}$ Beigel, Fernanda, "Las revistas culturales como documentos de la historia latinoamericana" Utopía y Praxis Latinoamericana 8,20 (2003)

${ }^{11}$ Artundo, Patricia, "Las revistas como objeto de estudio", Leer las artes. Las artes plásticas en ocho revistas culturales argentinas (1878-1951) dir. Saavedra Patricia y Artundo Patricia, (Buenos Aires: Facultad de Filosofía Y Letras, UBA, 2002)

${ }^{12}$ Delgado, Veronica, El nacimiento de la literatura argentina en las revistas literarias (1896-1913),(La Plata, Universidad Nacional de La Plata, 2009)
} 
Estas perspectivas facilitaran el estudio de la revista no solo desde el aspecto literario o cultural, sino como un conjunto de elementos que se complementan entre sí y brindan una original propuesta editorial.. Se debe destacar que la perspectiva biográfica permitió entender como la trayectoria de un intelectual no solo está en relación con la construcción y transformación de sus ideas, sino que es preciso estudiar los vínculos y modos de acercamientos a colegas y pares para el sostenimiento de prácticas que ayudan a encontrar y legitimar un espacio en el campo cultural.

A lo largo de los apartados, se intentará dar cuenta de las distintas voces en una misma revista que perseguían un mismo objetivo. En otras palabras, como diferentes tipos de lenguajes, es decir, el uso de fotografías, ilustraciones, caricaturas, poesías y narraciones, se conjugaron para defender la Rusia de los Soviets. Revista de Oriente no se limitó a difundirse entre intelectuales, sino que también se desplegó entre obreros, sindicatos, los grupos de vanguardia y el sector estudiantil interpelando a lectores de distintas clases sociales.

\section{Develando la realidad desconocida: El rol de Orzábal Quintana y Revista de Oriente}

La Revista de Oriente publicó su primer número en junio de 1925 bajo el impulso de Arturo Orzábal Quintana y con el apoyo de la Asociación de Amigos de Rusia. Orzábal Quintana fue un abogado nacido en 1892 en Argentina pero a partir de 1906 se trasladó, por las misiones militares llevadas adelante por su padre, a París.

Su familia pertenecía a la elite bonaerense y al provenir de los sectores dominantes contaba con la sociabilidad de la alta sociedad de la principal provincia del país. Es decir, experimentó la vida de la burguesía de fines del siglo XIX y principios del siglo XX, en la cual las grandes familias vivenciaron la europeización de sus costumbres, como señala Losada $^{13}$, habituaban los clubes de elites y realizaban continuos viajes a Europa. Esto le otorgó un capital simbólico, heredado tanto de Benjamina Quintana, su madre y pariente de la familia Alcorta, como de su padre por su trayectoria como oficial de carrera en el ejército argentino. De este modo Arturo Orzábal Quintana gozó con los beneficios que esto implicaba como realizar sus estudios allí y obtener el Doctorado en Derecho Internacional en la Universidad de París. Además de compartir la vida parisina entre escritores latinoamericanos y europeos que habitaban allí durante las primeras décadas del siglo XX.

Los años en la capital francesa de Arturo Orzábal Quintana se desarrollaron esencialmente entre 1910 y 1920. En este período París era el epicentro de la cultura occidental. Las tertulias y eventos atraían a escritores de todas partes del mundo y los latinoamericanos no fueron una excepción. Horacio Quiroga y Manuel Ugarte fueron dos ejemplos de argentinos que viajaron a Francia para conocer e inspirarse culturalmente, que como muchos otros hijos de las familias de la alta burguesía realizaron este tipo de

\footnotetext{
${ }^{13}$ Losada, Leandro, Historia de las elites en la Argentina. Desde la conquista hasta el surgimiento del peronismo, (Buenos Aires: Sudamericana, 2009)
} 
trayecto $^{14}$. Experimentaron los cafés y la bohemia europea de principio de siglo codeándose con poetas y artistas de países europeos y americanos.

Si bien Orzábal Quintana habrá conocido este círculo, al realizar sus estudios de grado y posgrado en la academia francesa también se nutrió intelectualmente de filósofos, especialistas y autores que luego repercutieron en los artículos que publicó en Buenos Aires. Además este abogado experimentó la Gran Guerra en territorio europeo. Las lecturas acerca de este acontecimiento mediante los periódicos y la misma vida cotidiana en las calles parisinas en constante amenaza impactaron en él. Las denuncias de los sufrimientos causados por la contienda, que tenía como principal causa al sistema capitalista, fueron constantes en sus redacciones donde se pueden notar la influencia de Henri Barbusse y Romain Rolland. Es muy probable que Orzábal Quintana haya conocido y escuchado a los antibelicistas en París durante el transcurso de la guerra lo cual lo diferenció en el campo cultural argentino.

A su regreso a Buenos Aires en 1920 se vinculó a los grupos reformistas cercanos a José Ingenieros, a quien reconoció como "maestro" y admiró su fervor revolucionario. Empezó a publicar en Revista de Filosofía, dirigida por el mismo Ingenieros, y en Nosotros, de Roberto Giusti y Alfredo Bianchi. Allí sus primeros trabajos abordaron los procesos diplomáticos luego de la Gran Guerra, tanto en Europa, Asia y América como lo acontecido en Rusia luego de la Revolución. A partir de estas intervenciones se acercó y encontró un espacio como analista internacional y publicista de la realidad soviética en el campo cultural argentino de los años '20. En ellos realizó descripciones y análisis que él consideraba pertinentes debido a la falta de información sobre la verdad de las clausulas en los tratados internacionales y la necesidad del conocimiento acerca de Rusia luego de la revolución.

Pero Arturo Orzábal Quintana se distinguió también por su capacidad organizativa de emprendimientos intelectuales diversos. Como la publicación que fundó y por ser un activo participante de la Asociación de Amigos de Rusia que funcionó en la Argentina al igual que en otros países europeos como Alemania, Francia e Inglaterra. ${ }^{15}$ A través de estas organizaciones fueron posibles los intercambios de documentos, noticias, eventos culturales y obras acerca de Rusia en distintos puntos geográficos del mundo, promoviendo a través de conferencias, actos y eventos la realidad soviética en el país. No obstante, entre sus objetivos también se encontraban: propagar vínculos entre los círculos intelectuales rusos y argentinos, analizar el espíritu de posguerra y el estado político y social y brindar ayuda económica a los estudiantes de cualquier parte del mundo que la precisaran para sus luchas ${ }^{16}$.

\footnotetext{
${ }^{14}$ Colombi, Beatriz, Viaje intelectual. Migraciones y desplazamientos en América Latina (1880-1915), (Rosario: Beatriz Viterbo editora, 2004)

${ }^{15}$ Sobre el buen camino. La cuestión del acercamiento cultural entre la Rep. Arg y la U.R.S.S.; Revista de Oriente; Número 2; julio 1925; p. 13.

${ }^{16}$ Revista de Oriente, $1,1,(1925)$ p. 34
} 
De este modo en junio de 1925 Orzábal Quintana y la Asociación de Amigos de Rusia crearon la Revista de Oriente a modo de divulgación de los objetivos de la agrupación. La publicación constó de ocho números con la aparición del último en septiembre de 1926. Sin embargo durante este año aparecieron solo dos ejemplares en junio y septiembre con números dobles pero de casi la mitad de páginas que los editados en el año anterior.

La Revista de Oriente por el espectro de sus colaboradores, sus objetivos y los temas trabajados se posicionó dentro del campo cultural como una revista de izquierda. Para Alejandro Eujanian y Alberto Giordano ${ }^{17}$ estas revistas se enmarcaron en una coyuntura que permitió que la idea de pueblo tomara relevancia en el espacio público a partir de la primera experiencia democrática del país. Además sostienen que estas se proponen como empresas capaces de proveer a los lectores populares las herramientas para alcanzar el cambio del sistema desigual e instalar un nuevo régimen social. En esta publicación esta concepción del pueblo apareció reforzada. Este era entendido como el protagonista de la revolución capaz de suprimir el sistema capitalista. En esta línea se puede sostener que la Revista de Oriente al utilizar recursos artísticos se distinguió de otros proyectos, como de la misma La Internacional, del Partido Comunista que también tenía como uno de sus objetivos difundir la realidad soviética. Respecto al contacto con esta publicación, es necesario destacar que en el órgano oficial del PC aparecieron publicidades y se recomendaba la adquisición de Revista de Oriente, pero sin otorgarle gran espacio. Esto permite inferir que existieron vínculos y cercanía con el Partido Comunista argentino pero Revista de Oriente contó con mayor apoyo por el sector intelectual y estudiantil. De todos modos, la aparición de estas distintas revistas, da cuenta del resultado de los efectos de la Revolución Bolchevique no solo en los partidos políticos, sino en el debate intelectual argentino.

La Revista de Oriente estuvo compuesta por un grupo variado de colaboradores entre actores políticos de izquierda, artistas plásticos y escritores tanto latinoamericanos como europeos. La mayor parte de los artículos informaron de las transformaciones ocurridas en Rusia y las consecuencias en el plano diplomático luego de la Primera Guerra Mundial que el grupo editorial creía necesario difundir ya que la "prensa grande" daba datos erróneos.

También los textos literarios abundaron en cada una de las ediciones con textos y poesías desde Alfonsina Storni, Álvaro Yunque o Gabriela Mistral hasta cuentos de escritores rusos. Al menos en los primeros cinco números, cada una de las páginas estuvieron acompañadas por ilustraciones de grabadores argentinos, caricaturas o fotografías tanto de esculturas o de sucesos de interés para la publicación.

\footnotetext{
${ }^{17}$ Eujanian, Alejandro y Giordano, Alberto, "Las revistas de izquierda y la función de la literatura: Enseñanza y propaganda", El imperio realista, ed. Gramuglio Maria Teresa, dir. Jitrik Noé, (Buenos Aires: Emecé editores, 2002)
} 
De este modo, la revista fue una revista cultural. Esta definición según Beigel ${ }^{18}$ entiende a las revistas como documentos históricos en donde confluyen trayectorias individuales y colectivas que al mismo tiempo se desarrollan como bisagras en tiempos de complejidades coyunturales. En este caso la trayectoria individual de Orzábal Quintana permitió los aportes del sector estudiantil, debido a su experiencia en la Unión Latinoamericana, como de algunos sindicatos con los cuales estuvo vinculado a través de actos y conferencias. Mientras que las trayectorias de escritores y artistas simpatizantes con ideas de izquierda apoyaron el proyecto otorgándole un rasgo distintivo. Para Patricia Artundo $^{19}$ quien toma el concepto de documento de cultura, agrega a la definición de Beigel el uso o apropiación de imágenes en estas. La autora sostiene que en este tipo de revistas es necesario analizar cuál es la imagen que intenta dar el proyecto de sí mismo mediante el uso de ilustraciones y fotografías o si el discurso escrito coincide con estas. Como también los problemas propios como las dificultades técnicas y económicas de sostener la reproducción de estas.

Revista de Oriente intentó dar una visión diferente de lo acontecido durante esos años de transformación y modernización política y cultural. Además, se desplegó en un campo en donde las funciones del intelectual y de este tipo de proyectos buscaban las formas de legitimar su función en él. Según las palabras de Verónica Delgado ${ }^{20}$ :

Las revistas pueden ser pensadas como espacios de definición y discusión de las propias prácticas intelectuales, también puede afirmarse que tales intervenciones ponen en escena una actualidad fechada: la del mundo cultural que le es contemporáneo, configurado y enjuiciado desde la perspectiva propia. Así, se ofrecen como material privilegiado para leer en ellas no sólo las modulaciones diversas de aquella demanda, sino también, sus efectos y los cambios que marcan el camino.

El primer número presentó una estructura que luego se repitió en los siguientes. Luego de la portada ilustrada con imágenes relacionadas con la clase proletaria, la primera página se titula "Notas de Actualidad", allí se publicaron noticias tanto nacionales como internacionales. En las cuales se criticaba con cierta ironía las injusticias económicas, sociales o políticas que ocurrían en distintos países regidos por el capitalismo. Si bien en este proyecto el objetivo era la difusión de la realidad soviética cedió a las novedades diplomáticas mundiales.

El fin de Revista de Oriente, como se planteó en más de una ocasión, era divulgar la verdad de lo ocurrido en Rusia que muchas veces era tergiversado por la prensa oficial, según el grupo editorial. Por lo tanto, se pueden leer en las páginas de la publicación los siguientes modos de denunciar los hechos "manipulados" por lo que el comité editorial identificaba como "prensa grande":

\footnotetext{
${ }^{18}$ Beigel, Fernanda, op. cit.

${ }^{19}$ Artundo Patricia, op. cit.

${ }^{20}$ Delgado, Veronica, op. cit.
} 
La prensa grande de Europa y América se ha encargado en estos últimos tiempos en una forma insidiosa sobre la forma en que los bolcheviques administran las joyas de la Corona Rusa. El reciente remate de ejemplares secundarios ha dado motivo para esta campaña. Pero todos los escritores que han estado en Rusia reconocen el celo con el que el Gobierno de los Soviets guarda los tesoros de la época del zarismo. ${ }^{21}$

Esta cita es una crítica directa a las noticias que difundían algunos periódicos. La utilización del término "grande" identificaba a los periódicos que contaban con un sostenimiento económico importante y con un mayor número de lectores, a diferencia de las revistas de izquierda como Revista de Oriente. La denuncia acerca del mal uso de las joyas de la corona zarista por parte de los bolcheviques era enfrentada al testimonio de escritores, no mencionados, que habían visitado Rusia y por lo tanto tenían, para Revista de Oriente, la voz de la verdad. Lo cual les permitía cumplir su propósito de mostrar a su público lo que realmente ocurría en el país de los soviets.

La revista continuaba dividiéndose de la siguiente manera: uno o dos artículos "centrales" que ocupaban de dos a tres páginas, muchas veces acompañados por caricaturas, fotografías o ilustraciones. De este modo, no estaba compuesta solo de recursos narrativos sino que se encontraban lenguajes gráficos de la realidad de Europa y Latinoamérica.

La constante aparición de escritos de las injusticias mundiales fue un rasgo de la Revista de Oriente. Entendía a estas como el sufrimiento de los individuos desprotegidos y oprimidos por el sistema capitalista que padecían hambre, cuidados de salud y educación. Para los colaboradores era necesario transmitir esto en las páginas debido a que el público precisaba tomar conciencia de la realidad que habitaban. También las distintas colaboraciones referían a las consecuencias de la Primera Guerra y la pobreza que generó en los pueblos europeos. A la vez, indicaban como el sistema capitalista provocaba la ambición de los gobernantes de las potencias mundiales y estos se aprovechaban de los pequeños estados.

Los temas de estos artículos constaban de crónicas de acontecimientos políticos europeos internacionales y sobre todo de los cambios a favor del pueblo llevados adelante en la U.R.S.S Tanto los textos literarios como los de análisis político remarcaban el desequilibrio de poder entre las clases sociales. Puede entenderse como un modo de concientizar a los sectores obreros a los cuales llegaba el proyecto editorial para que estos tomen parte de la acción que generaría el cambio. Por ejemplo en la siguiente cita se describía:

La fuerza del capitalismo reposa en parte sobre la miseria de los campesinos pobres. En las guerras imperialistas es a los campesinos a quienes se les impone los más terribles sacrificios; a excepción de un puñado de ricos cultivadores, las masas de los campesinos tienen intereses comunes con los obreros. Solo una

21 "Los museos de Rusia"; Revista de Oriente, (1925) 1,3. P.25 
lucha en común de los campesinos y los obreros puede abatir el capitalismo; solo su colaboración puede asegurar el bienestar y el desarrollo de la paz de la Humanidad entera. ${ }^{22}$

Aquí, es evidente como el comité editorial tenía como objetivo concientizar a sus lectores de la necesidad de la erradicación del capitalismo. Además se observa cómo se dirigían a dos grupos específicos: los campesinos y obreros. A los cuales se llamaba a la unión y luego a la acción ya que sin ellos ninguna transformación podría ser alcanzada. Como se ha mencionado, el Partido Comunista en este período también enfocó su actividad en el llamamiento del sector proletario llevando adelante actividades en las fábricas. En Revista de Oriente se relata, manteniendo su autonomía editorial, como esto también era llevado adelante por los integrantes, especialmente Orzábal Quintana, del proyecto. Lo cual permite inferir que las estrategias en este aspecto no difieren entre el partido político y este proyecto que no se reconocía como partícipe de este.

Luego aparecían otra serie de artículos más breves, generalmente biografías de escritores e intelectuales o crónicas de acontecimientos de la vida cotidiana. Estos pueden ser entendidos como una de las maneras de incorporar en las mentalidades, tanto de obreros como de intelectuales, el verdadero papel de estos últimos al momento de llevar adelante la revolución: guiar al pueblo para que este lograra liberarse de las cadenas económicas y culturales que imponía el capitalismo.

En uno de los números se eligió a Rogelio Irurtia ${ }^{23}$, el escultor argentino. Se señalaba como supo entender el espíritu del pueblo y representarlo en sus obras a diferencia del arte burgués que no captaba esta esencia. Este caso merece un mayor análisis debido a que Rogelio Irurtia no pertenecía a las vanguardias que participaron de Revista de Oriente ni compartía la estética revolucionaria como el caso de los grabados que aparecieron en las portadas. Por el contrario, identificaba al academicismo. No obstante, en los diferentes números de la revista, se pudo observar que el arte no era entendido según sus corrientes, sino por su función y su poder en los receptores. El arte por su impacto en la sociedad. Aun así, la reseña a Irurtia es una excepción debido a que no se encontraron otras acerca de artistas que no pertenecían a los nuevos movimientos.

La definición y discusión de las prácticas artísticas e intelectuales, retomando a Delgado, estuvieron presentes en Revista de Oriente. Como se ve en el caso del escultor, se señalaba cómo un actor del campo cultural podía aportar a la educación del pueblo mediante su obra. También aparecieron artículos en donde se reconocía la dedicación a la Revolución por parte de algunos intelectuales. Esto permite distinguir en esta publicación un modelo de intelectual y de prácticas culturales necesarias: debían estar al servicio del

\footnotetext{
${ }^{22}$ Dombal, "Campesinos y obreros", Revista de Oriente; 1,3, (1925). P. 32

${ }^{23}$ Rogelio Irurtia (1879- 1950) fue un escultor argentino representante del academicismo. En 1899 ganó un concurso que le permitió estudiar en París donde perfeccionó su obra y vivió 20 años. A su regreso fue profesor y miembro de la Academia Nacional de Bellas Artes. Su obra no formó parte de las vanguardias de la época ya que se lo identifica con la corriente naturalista.
} 
pueblo y el cambio político y social. Lo cual brinda información acerca de la identidad que el proyecto buscó sostener y legitimar en el campo cultural de los años '20.

Por lo tanto, se destaca que para el grupo editorial de Revista de Oriente el rol del intelectual o del artista era concebir la realidad y desplegar en su obra este espíritu movilizador capaz de ser instalado en las masas populares, enalteciendo a los individuos. Esta idea fue defendida y cristalizada en todos los números de la revista. La herramienta precisa para transformar el sistema social con la ayuda de todas las clases sociales era el arte.

Este objetivo, resaltado por el proyecto editorial en cada número, puede ser entendido como el resultado de la influencia recibida desde las propias políticas culturales de la U.R.S.S. Anatole Lunatcharsky fue el Comisario de Instrucción Pública encargado de crear el clima apropiado para la expansión y despliegue del proletkult. Como se indicaba en uno de los números, la Asociación de Amigos de Rusia contaba con el apoyo directo del Ministerio de Instrucción Pública soviético.

El arte de este movimiento se caracterizó por exaltar la imagen "bella" y heroica del trabajador, ilustrar la vida en las fábricas, quebrar las convenciones de la estética burguesa, intentar fusionar el arte con la vida industrial y llevar la cultura a las masas que se consideraban prerevolucionarias, es decir a las que aún no concebían un régimen que no sea el zarista ${ }^{24}$ (Mally, 1990). Junto a Lunatcharsky, es Alexander Bognadov ${ }^{25}$ quien consideraba necesario para la transformación de la sociedad el despliegue de la vía cultural, además de la política y económica, e impulsó este camino. En el siguiente apartado, se verá en detalle la relevancia y la influencia de esta línea en el uso del arte en Revista de Oriente.

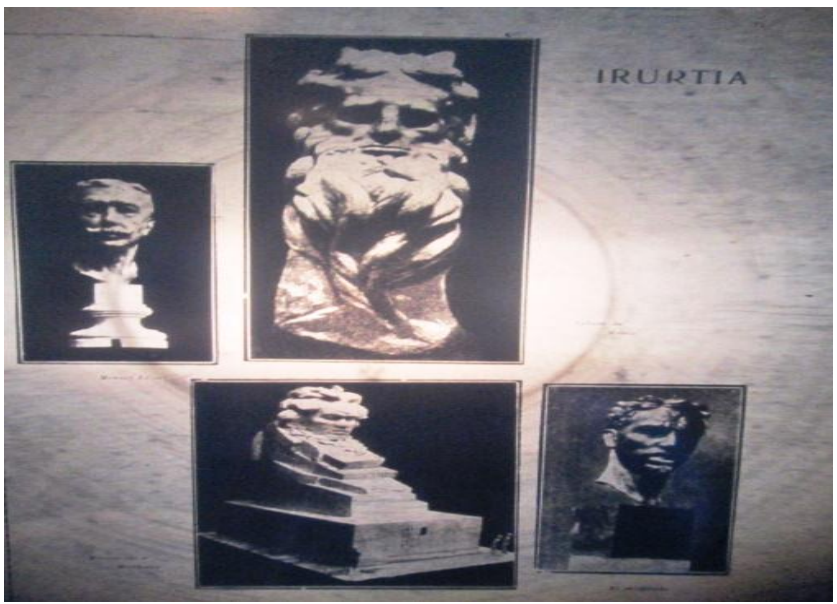

Fotografía $\mathrm{N}^{\circ} 1$ : Página con esculturas de Irurtia que acompañan el artículo.

\footnotetext{
${ }^{24}$ Mally, Lynn, The culture of the future. The proletkult movement in revolutionary Russia, (Berkeley: University California Press, 1990)

${ }^{25}$ Científico ruso, alineado a las ideas bolcheviques.
} 
Este tipo de fotografías eran una constante en la publicación, especialmente en el centro donde aparecía la sección "Notas gráficas de Rusia". Esta ocupaba el lugar central y en los distintos números contó con fotos acerca de las transformaciones en museos y monumentos, la participación de artistas soviéticos en exposiciones de artes europeas, eventos llevados adelante en el propio país y algunas imágenes de obreros trabajando en condiciones justas e igualitarias. En ninguno de los artículos de la revista se halló una crítica de la realidad rusa que perjudicara las condiciones de vida de los trabajadores o campesinos. Se la enfrentó al régimen capitalista y por lo tanto se la concibió como el modo de modificar la situación del proletariado.

El análisis de las imágenes que se reprodujeron permitió reconstruir la idea que intentó darse el proyecto a sí mismo ${ }^{26}$. En este trabajo se ha seleccionado las imágenes más ilustrativas y particulares que aparecieron en los números de Revista de Oriente, para que el lector comprenda su significado como complemento a la posición ideológica defendida en los artículos y la búsqueda de atracción del público. Es decir, la revista apoyó la causa revolucionaria y buscó construir un propio universo de lectores que se sumaran a este objetivo mediante el reconocimiento de las políticas soviéticas. Cada una de las ilustraciones y fotografías sostuvieron un modelo social distinto al capitalista el cual el grupo de colaboradores creía justo e igualitario.

Tanto la reproducción y la ilustración de los tópicos trabajados en los artículos dan cuenta de la estrategia de Revista de Oriente para la transformación social y del "espíritu" del proletariado mediante el uso de expresiones estéticas, sean plásticas como literarias. Estas eran el instrumento que les permitió transmitir a los trabajadores sus propuestas. Así estos alcanzarían conciencia de clase y lucharían por el cambio social. Las temáticas representadas en los grabados o dibujos, las poesías y cuentos que aparecieron en la revista narraban las experiencias de la vida cotidiana del obrero o trabajador o las distintas formas de injusticia que regía en el sistema capitalista. El arte aportaba un camino alternativo para que los trabajadores se acercaran a la cuestión revolucionaria y pudieran reflexionar sobre su papel y posterior acción de sus prácticas.

\footnotetext{
${ }^{26}$ Artundo Patricia, op. cit.
} 

artists for the Revolution: Revista de Oriente, 1925-1926, Revista Izquierdas $\mathrm{N}^{\circ}$ 25, Octubre 2015, IDEAUSACH, ISSN 0718-5049, pp. 165 - 195

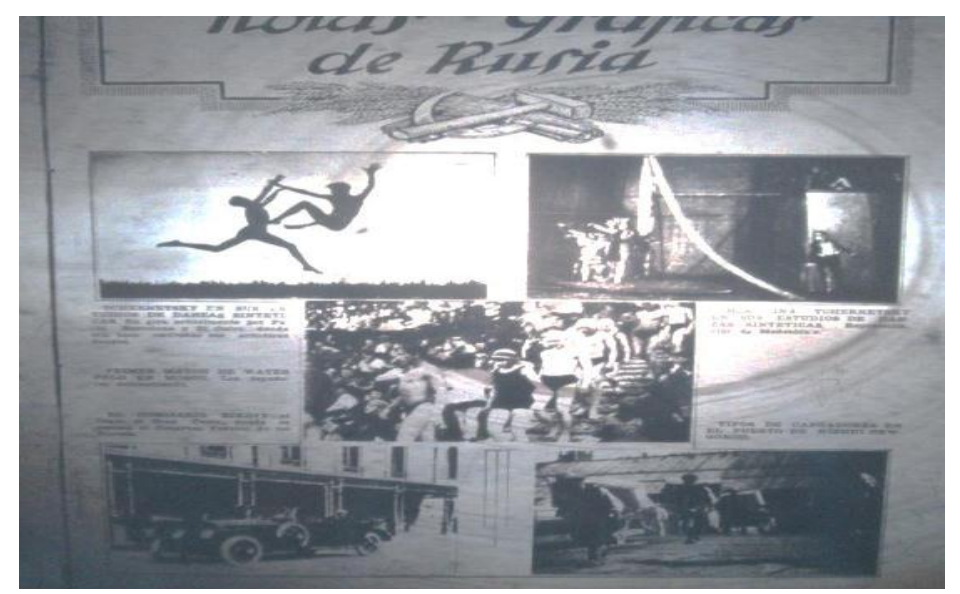

Fotografía 2: Página de Revista de Oriente "Notas Gráficas de Rusia"27

La publicación a partir de la segunda mitad de cada número, solía ubicar textos literarios y poéticos, algunas veces rodeados de crónicas o algún artículo o reseña de los eventos llevados adelante por la Asociación de Amigos de Rusia. Los temas trabajados en los cuentos y poesías acompañaban la visión de los artículos informativos: la existencia en una sociedad desigual e injusta. Pero también ayudan a reflexionar sobre la posibilidad de la transformación a partir del ejemplo ruso. En los versos de la poesía de Esteban Pavletvich, como se indicaba en Revista de Oriente, un estudiante peruano perseguido por el gobierno de Leguía, se vislumbraba esto:

\author{
(...) Aurora roja. \\ De lo alto de la torre \\ ha caído Jesús. \\ La hoz y el martillo redimen \\ las impurezas de la cruz. \\ "Todo el poder a los Soviets" \\ gritan a coro \\ los 180.000 obreros de la ciudad. $(. . .)^{28}$
}

Cada uno de los versos remitía a acontecimientos políticos pero narrados con una estética diferente a lo que podría leerse en crónicas o textos informativos. Es decir, recurriendo a elementos propios del arte como metáforas o comparaciones que matizaban el relato puramente político. Aurora roja sugiere los colores con los se identificaba a la Revolución además el término aurora también indica la idea de una señal, quizás pensada para ser vista y entendida en otras partes del mundo. Luego se leía una crítica directa a la

\footnotetext{
${ }^{27}$ Revista de Oriente, 1, 4, (1925)

${ }^{28}$ Pavletevich, Esteban, “Los poemas de la Revolución”, Revista de Oriente 1,8 (1926)
} 
religión cristiana, lo cual refiere a la idea de ruptura con todo orden establecido no solo el político y económico. De este modo, el público puede optar por leer extensos artículos, muchas veces con datos estadísticos muy precisos o narraciones con recursos estéticos pero que ayudaban a adquirir conciencia de las transformaciones alcanzadas o potenciales.

Además, uno de los versos citados, correspondía al lema de Lenin Todo el poder a los soviets. Por último, el pueblo aparecía como legitimador de este acontecimiento, ya que ellos coreaban el lema de su líder. Esto puede pensarse como uno de los modos de instaurar en los lectores una clara línea política a través de una obra artística, el poema. Nuevamente, este tipo de expresiones muestra un modo de acercar ideas políticas de transformación a un público variado. Retomando a Artundo, en este proyecto editorial la publicación de textos literarios que coincidían con la propuesta ideológica de las imágenes y fotografías, reafirmaba la posición política y cultural de la revista.

Al reflexionar sobre el público al cual se dirigió Revista de Oriente se señalan tres grandes grupos: intelectuales, obreros y estudiantes. Esto se infiere a partir de las temáticas trabajadas en las páginas ya que existieron publicaciones sobre los ataques a los estudiantes chinos y peruanos, como de las actividades del estudiantado argentino. Por otra parte, el contar con la colaboración o el reconocimiento de Mariátegui o reproducir ensayos de Barbusse $^{29}$ provocaba el interés de intelectuales del campo cultural latinoamericano. El periodista y escritor francés fue uno de los fundadores del Partido Comunista de su país y cuyas obras antibelicistas y críticas del capitalismo fueron leídas por muchos intelectuales latinoamericanos izquierdistas. Por lo tanto, que se le brindara un espacio y reconocimiento en la revista reafirmaba el prisma mediante el cual analizaban la realidad europea y americana.

Mientras que las caricaturas y las obras literarias reproducidas en la publicación permitían una lectura más sencilla y didáctica que informaba acerca del escenario político sin las especificidades y posibles dificultades que los documentos escritos por especialistas. También, se deben mencionar las secciones no regulares encargadas de difundir sobre sindicatos y organizaciones obreras argentinas, como el caso del Sindicato del Mueble o la Federación Gráfica Bonaerense. Estos se sumaban a las descripciones del funcionamiento de las fabricas soviéticas, demostrando la solidaridad que existía entre la clase proletaria. $\mathrm{Al}$ igual que es otro punto de contacto con la actividad del Partido Comunista.

\footnotetext{
${ }^{29}$ Henri Barbusse; "Barbusse contra el barbussismo"; Revista de Oriente.1, 6. (1926); p. 12
} 


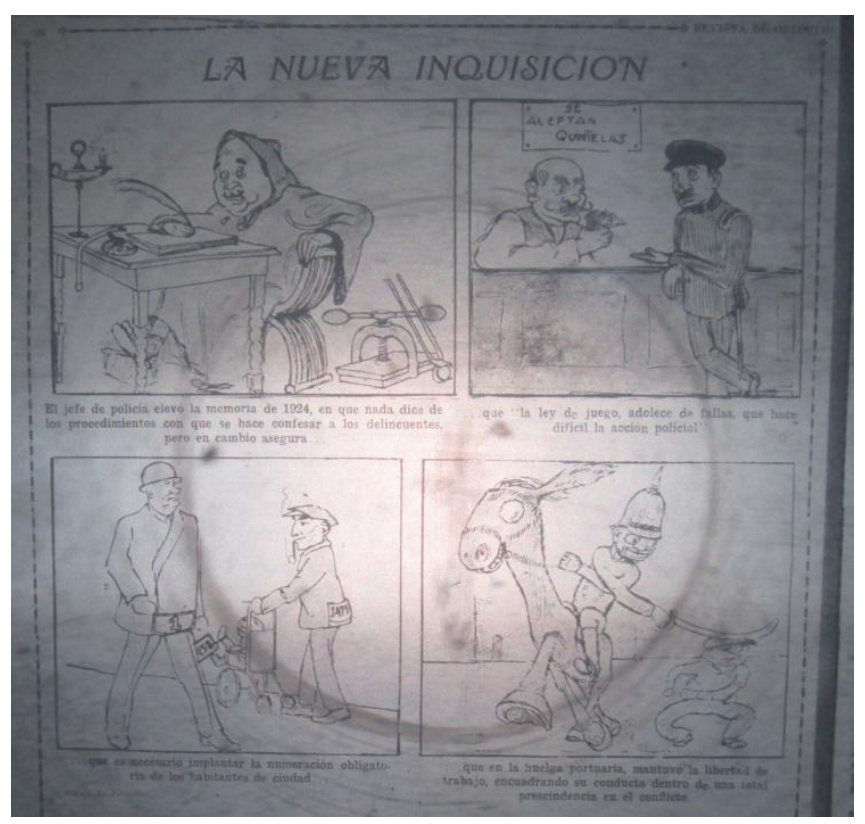

Ilustración 2: Caricatura acerca de la actuación policial ${ }^{30}$.

También en Revista de Oriente, aparecieron algunas líneas de crítica hacia el funcionamiento de las instituciones argentinas. En la caricatura de arriba se denunciaba la actuación de la institución policial. Se la ilustraba como corrupta y violenta (véase ilustración 2). Este tipo de evaluaciones se realizó en menor medida que toda aquella relacionada con los acontecimientos rusos. Sin embargo, es importante destacar que el principal punto que los colaboradores de la revista señalaban que la corrupción de las instituciones era causa del funcionamiento del Estado capitalista.

A pesar de la innovación de Revista de Oriente, las características que la diferenciaban de otras publicaciones y el reconocimiento obtenido en distintos espacios intelectuales esta no superó el año (discontinuado) de salida a la venta. La principal causa fue la económica. A partir del segundo número se pedía la colaboración para la venta y distribución de la publicación. Artundo aclara que el principal obstáculo de este tipo de revistas eran los costos de impresión ${ }^{31}$, lo cual en Revista de Oriente fue factible. Al pasar los meses, el pedido se hacía más desesperante y se lanzó un empréstito y rifas de cuadros de artistas argentinos para solventar la continuidad de este proyecto. Dejó de aparecer de manera regular a partir de su quinto número, en noviembre de 1925, reapareció en enero de 1926 con un número doble y en julio de ese mismo año también con un número doble. Es importante destacar que las dos últimas ediciones contaron con no más de 25 páginas cuando los números del año 1925 llegaron a tener 44. Esto es un modo de comprender que

\footnotetext{
${ }^{30}$ Revista de Oriente, 1,1. (1925)

${ }^{31}$ Artundo, Patricia, op. cit.
} 
realmente los costos en las copias de los ejemplares dificultaron la aparición y la permanencia de esta revista. Por otra parte, a modo de inferencia se sostiene que no obtuvo la respuesta esperada por parte del público a la cual estaba dirigida. Quizás por contar dificultades de distribución o el campo cultural no fue propicio para una venta que permitiera el sostén y reproducción de la publicación.

Es así, como Revista de Oriente buscó y encontró el modo de diferenciarse a través de sus documentos exclusivos obtenidos a través de la Asociación de Amigos de Rusia y de las colaboraciones de textos literarios e imágenes que acompañan las prerrogativas y su posición respecto a la función cultural y artística del intelectual.

\section{El arte para la vida cotidiana del obrero: Literatura e ilustraciones de Revista de Oriente}

Los recursos gráficos estuvieron muy presentes en este proyecto editorial. Las portadas e imágenes que acompañaron los distintos tipos de textos en la revista demostraron la importancia que tuvo para la dirección de la publicación este tipo de expresión artística. Estas ilustraciones definían la orientación ideológica de la revista al representar el mundo obrero y reproducir los eventos rusos y del campo político y cultural latinoamericano.

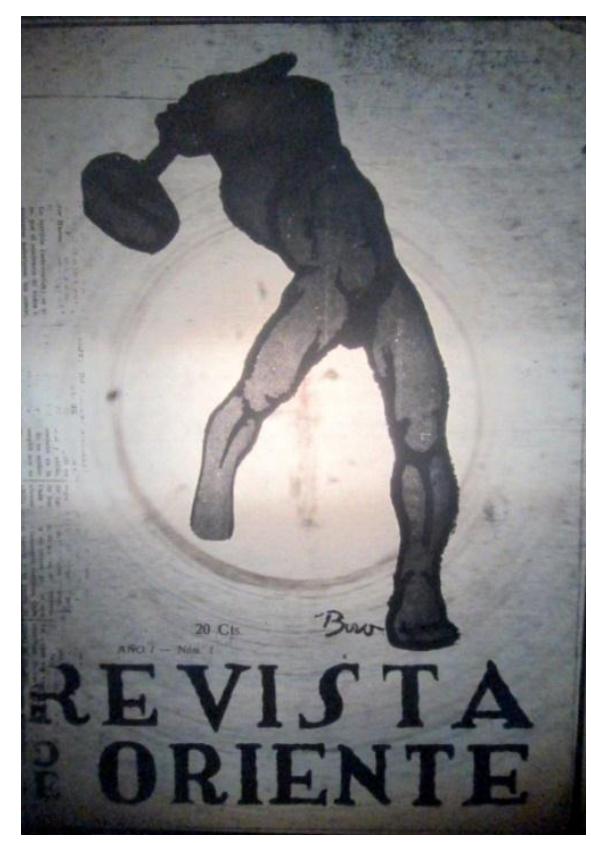

Ilustración 3: Portada Revista de Oriente N${ }^{\circ}$, junio 1925. 

artists for the Revolution: Revista de Oriente, 1925-1926, Revista Izquierdas $\mathrm{N}^{\circ}$ 25, Octubre 2015, IDEAUSACH, ISSN 0718-5049, pp. 165 - 195

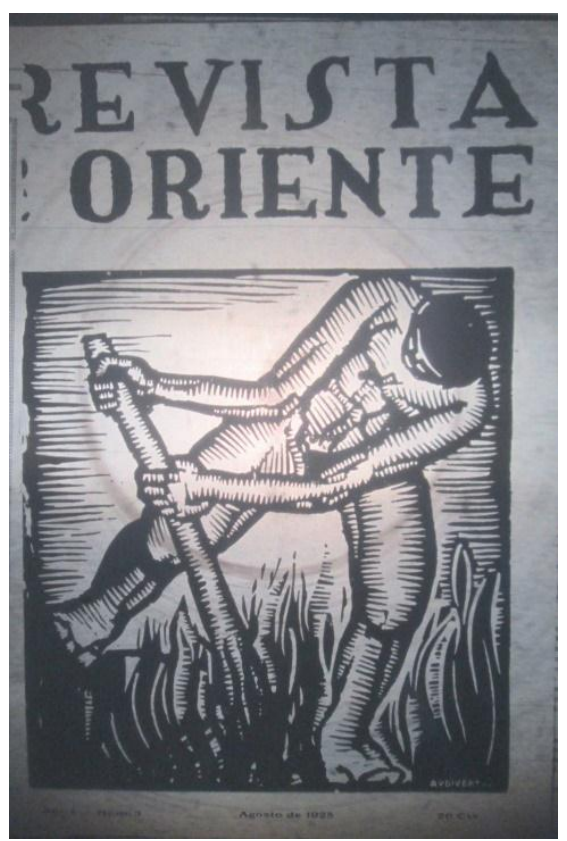

Ilustración 4: Portada Revista de Oriente N³, agosto 1925.

Ambas portadas estaban ilustradas con la misma temática: dos hombres realizando tareas manuales o con herramientas de trabajo en mano. Es posible pensar que esto se debió al interés de buscar en el público un lector que se sintiera identificado y que se viera representado en la revista. En este período el grabado tuvo relevancia en los grupos artísticos de izquierda. Como señala Silvia Dolinko en su estudio acerca de Guillermo Facio Hebecquer y donde realizó una descripción de los Artistas del Pueblo ${ }^{32}$, el uso del grabado ofrecía la posibilidad de multiplicar las obras para la llegada a un público masivo además de reivindicar el arte como trabajo manual ${ }^{33}$. El artista de esta forma se posicionó a la par de los obreros mostrando a través de ilustraciones los padecimientos de las masas populares y sus esfuerzos en las tareas cotidianas.

A través del recorrido por las páginas de Revista de Oriente se observó que el arte tuvo un papel fundamental para la tarea que se proponía. Es decir denunciar las injusticias y también mostrar cómo las condiciones de vida de los obreros mejoraron luego de la revolución en Rusia. En las distintas ediciones, las imágenes que aparecieron suelen exponer figuras que padecían o sufrían las consecuencias del sistema capital definido en ella como desigual y opresor. Por lo tanto, el uso de obras artísticas ayudó a que las denuncias presentes en cada uno de los artículos fueran comprendidas de manera didáctica

\footnotetext{
${ }^{32}$ Esta agrupación de artistas argentinos funcionó entre 1910 y 1935 es considerada referente en el uso de la técnica del grabado. Estuvo conformada por José Arato, Adolfo Belloq, Guillermo Facio Hebequer, Agustín Riganelli y Abraham Vigo. ese tono de definiciones de autores que habría que modificar.

${ }^{33}$ Dolinko, Silvia, "De la revisión del artista del pueblo al cuestionamiento institucional. Lecturas sobre Guillermo Facio Hebequer"A contracorriente 8,2 (2011)
} 
por un público diverso y no puramente intelectual. Además tomando la idea de Graciela Montaldo $^{34}$ y lo que ella propone para el grupo Claridad, la estética elegida para "educar" al pueblo era el realismo. El estudio de esta autora estudia la pedagogía presente en el proyecto de Zamora. No obstante, Revista de Oriente ofrece una particularidad respecto a lo que se intenta transmitir a los sectores proletarios. No es como en el caso de los proyectos de la editorial Claridad, instalar la moral en el pueblo, sino lograr que este «eduque» su espíritu para llevar adelante la revolución.

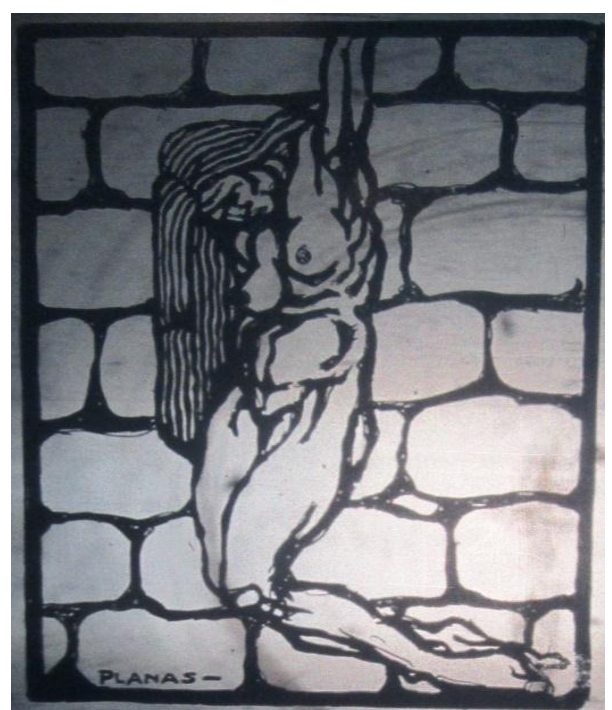

Ilustración 5: Grabado de Planas que acompaña el texto del Prof. Goldschmit "La Prostitución".

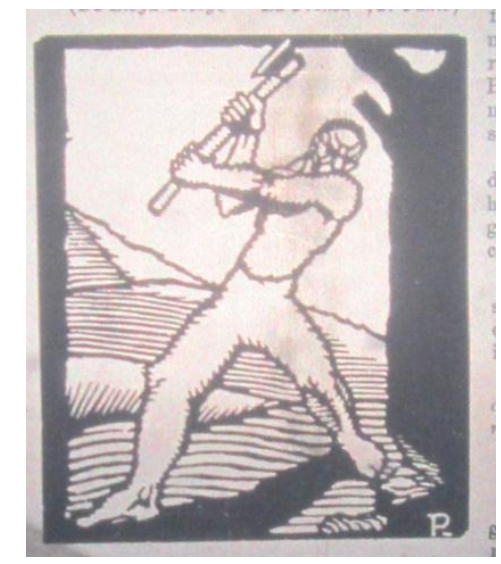

Ilustración 6: Grabado de Planas que ilustra una sección inaugurada en el último número de la revista.

34 Montaldo, Graciela; "La literatura como pedagogía, el escritor como modelo, Cuadernos hispanoamericanos 445 (1987) 
Estos dos ejemplos sirven para analizar la imagen que se buscó representar de las clases populares. Por un lado, en el primer dibujo, se mostraba a una mujer que ejercería la prostitución, según el texto que acompañaba. Se la observaba en una posición de sufrimiento y de esclavitud, al tener sus manos atadas, indicaría que es incapaz de liberarse de su padecimiento. El texto del profesor Goldschmidt sostenía que la venta de la sexualidad de la mujer era consecuencia del sistema capitalista que las explotaba para que estas pudieran sobrevivir.

Por otra parte, es interesante como en el segundo ejemplo, se puede ver un obrero o un trabajador con el hacha en alto y con rostro seguro y determinante. Esta imagen es el centro de la sección titulada "El hachador" que apareció por primera vez en el número 8 y 9 de Revista de Oriente, es decir el último. En ella se convocaba a todo lector que quisiera colaborar con noticias, dichos o datos que les parecieran injustos o absurdos tomados del espacio público. Por lo tanto, se comprende como un intento de incorporar no solo a especialistas o escritores con experiencia en publicaciones periódicas sino que también era posible que los sectores populares formaran parte de la edición de la revista. En consecuencia, se encontraron estas dos posiciones, por un lado el obrero explotado, ya sea mujer u hombre y por otro, la capacidad de estos para poder cambiar la realidad que los rodeaba y oprimía.

Según la idea ya mencionada de Patricia Artundo ${ }^{35}$, este tipo de publicaciones permiten un estudio de la visualidad que da lugar a analizar la propia imagen que proponía la revista sobre sí misma. En el caso estudiado, las imágenes representaban, como se ha demostrado, a la clase trabajadora. Esto indica el público que se buscaba atraer, en otras palabras la revista intentó ser accesible a toda clase social y se posicionó como intérprete de los sectores más desfavorecidos. Este concepto no coincide plenamente con el de Beigel señalado anteriormente, pero se complementan y son apropiados para el estudio de este trabajo. Mientras Beigel ofrece una explicación para entender a las revistas dentro del campo cultural y la función de estas, Artundo explica las características de este tipo de publicaciones culturales y artísticas.

No obstante, existió una cantidad importante de retratos de intelectuales y escritores que acompañaron las biografías de estos o sus textos publicados en Revista de Oriente. De esta forma también se define como un proyecto realizado por y para especialistas en los temas trabajados. Por lo tanto, confluyeron tanto un grupo de artistas que apoyaba la causa revolucionaria y a través de la expresión artística intentó difundir y apoyar la revolución, de una forma didáctica. Contó con un grupo de intelectuales dedicados a explicar los cambios de la realidad política rusa y mundial para lectores más especializados en este tipo de lecturas. Respecto a esto, es posible pensarlo como el resultado del promotor de este proyecto, Orzábal Quintana vinculado a intelectuales durante toda la década y escribió en revistas destinadas a académicos y a un público partícipe del mundo cultural. En esta publicación reunió tanto a este sector como al proletariado. Nuevamente, la trayectoria

\footnotetext{
${ }^{35}$ Artundo, Patricia. op. cit.
} 
personal de este abogado es crucial para comprender el espectro y despliegue en el campo cultural de la revista

Al igual que la proliferación de fotografías e imágenes, las poesías y textos literarios se encargaron sobre todo de ilustrar la vida cotidiana de los sectores populares y las consecuencias del sistema capitalista en sus vidas. Los cuentos que aparecieron sistemáticamente en cada número relataban las experiencias de trabajadores ya sea burocráticos como el cuento de Raúl Scalabrini Ortiz "iTe vas, te vas!" o en el caso "La Sal" de Babel, la situación en Rusia. En el primer caso, el autor argentino, quien en ese momento ya había publicado una serie de cuentos, La manga y años más tarde sería conocido por El hombre que está solo y espera y por su crítica a los capitales ingleses en $E l$ imperialismo británico en el Rio de la Plata, retrataba la vida de dos compañeros de trabajo. Ambos habían trabajado por mucho tiempo juntos en una oficina de embarques pero apenas se dirigían palabras debido a que cada uno estaba inmerso en su propia individualidad. La enseñanza que puede inferirse es que el capitalismo moldeaba a los sujetos para que fueran indiferentes hacia el otro sin sentir empatía estando en la misma situación de explotación laboral. Hacia el final de la obra también surge el desasosiego de uno de los personajes, al reflexionar cuando veía los barcos irse por la ventana:

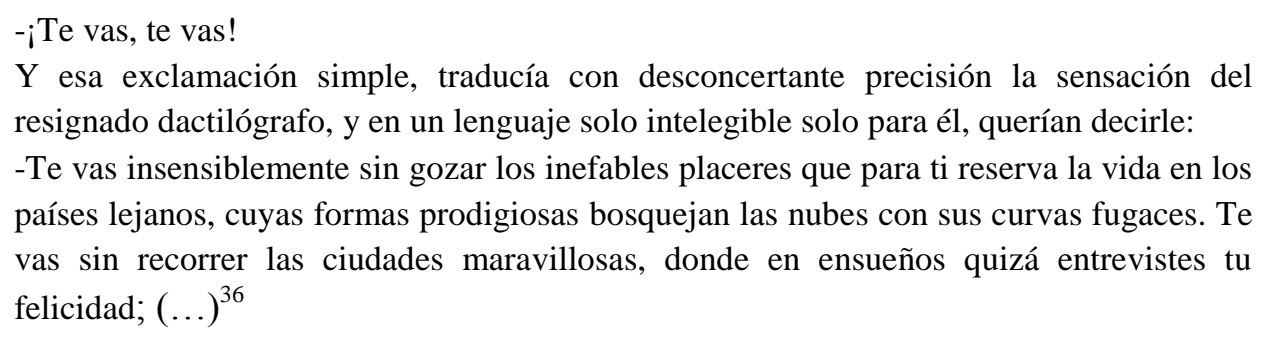

Por su lado, el cuento ruso detallaba como una mujer campesina robaba a soldados que luchaban por la revolución de la cual ella sería beneficiaria. Pero al estar preocupada por su propio bienestar decidía hurtar el alimento de los defensores del cambio social. El narrador, reflexiona acerca de todos los enemigos que tenían que vencer para alcanzar la victoria definitiva al igual que sabe que la mujer no actuaba conscientemente sino como consecuencia del sistema capitalista.

La literatura en Revista de Oriente tuvo entonces una función pedagógica ya que las conclusiones de estos cuentos buscaban que el lector se replantease sobre su propia acción respecto a sus pares. En el mejor de los casos, provocaría que este transformara sus actitudes de forma "honesta" y para alcanzar "el bienestar mayor", es decir de toda la sociedad. Graciela Montaldo ${ }^{37}$, en su trabajo acerca de Claridad, vinculada al grupo Boedo, plantea la relación: literatura-escritor-publico, la autora señala como esto se presentó en la publicación que analizó como un modo de "educar al ciudadano". Si bien la revista

\footnotetext{
${ }^{36}$ Scalabrini Ortiz, Raúl; “¡Te vas, Te vas!”; Revista de Oriente 1,2 (1925) p. 27

${ }^{37}$ Montaldo, Graciela, op. cit.
} 
Claridad tuvo sus particularidades, es posible trasladar esa idea con lo propuesto por Revista de Oriente, interpretando no una educación del lector para que este incorpore elementos de moral, sino que sea educado para habitar un nuevo sistema social, la transformación hacia el socialismo que se alcanzaría a través del cambio de subjetividad política de los obreros.

Esta misma autora señala como la literatura en la revista de izquierda tuvo un enlace directo con la realidad o intentó ser un reflejo de la misma. Esto se puede ilustrar con las poesías que fueron publicadas en Revista de Oriente:

\section{Con las manos vacías \\ Amor, Amor: \\ Tú eres rico y pródigo, Deme siquiera, \\ Señor, una limosna... \\ ¿Una limosna? \\ -me replico severo- \\ Te conozco, mendigo; \\ Pides con humildad, \\ Pero eres orgulloso \\ Y nada te conforma \\ ¡Y me dejo marchar \\ Con las manos vacías; \\ El señor de los señores, \\ El que a todos da risas \\ Y puñados de rosa! ${ }^{38}$}

En este caso, el poema relataba como un señor hacía caso omiso a las demandas de un mendigo de la ciudad. El realismo caracterizó esta poesía como a otras, en las cuales se reflejó la frialdad de personas de bienestar económico frente a los padecimientos de los sectores más desfavorecidos. Específicamente en la última estrofa existía una crítica hacia la hipocresía que cubría a la mayor parte de la sociedad. El hombre que se negaba a darle una ayuda al indigente, a otros "da risas y puñados de rosas". Es así como se representaba los avatares de la vida cotidiana de la ciudad capitalista.

En la misma página, se publicó una poesía de Clara Beter, el personaje creado por Cesar Tiempo, famoso por sus escritos publicados en Claridad que remitían a la vida de prostitución soportada supuestamente por esta autora. En la cual se vislumbraba otro tópico que se repitió en otros poemas o ilustraciones, como en los artículos: la esperanza de una transformación social posible.

\footnotetext{
${ }^{38}$ Delgado Fito, Revista de Oriente, 1,5 (1925) P. 24.
} 


\section{Frente al Océano}

¿Qué día, qué día traerán estas aguas

La nave en que vengan los hombres de allende?

Los hombres que digan la buena palabra

Que esperamos siempre?

Los hombres que vengan fornidos, viriles,

Trayendo la nueva simiente de amor,

Que forje una raza de hermanos, unidos

Por el corazón.

Los hombres que vengan sonrientes y sanos

Vibrando en sus bocas canción de esperanza,

Los hombres que tengan las almas iguales

En todas las patrias.

Yo sé que algún día traerán estas aguas

La nave en que vengan los hombres de allende,

Los hombres cordiales y fuertes que traigan

La nueva simiente. ${ }^{39}$

En este caso, no se realizaba una crítica directa a la cultura del sistema capitalista, sino que se instalaba una visión esperanzadora acerca de los cambios posibles: la llegada de un hombre nuevo capaz de modificar el sistema social por uno más justo e igualitario. El hombre que llegaba cruzando el mar era el hombre revolucionario. La instalación de una sociedad igualitaria también aparecía ilustrada mediante la estética poética. Por ejemplo: los hombres que tengan las almas iguales en todas las patrias. Este poema representaba el otro discurso en toda la revista. Por un lado, la denuncia al orden social y por otro la potencia de una transformación del mismo.

Todas estas expresiones artísticas se desarrollaron dentro de un circuito de intercambios entre los distintos grupos vanguardistas presentes en Buenos Aires. Si bien se ha mencionado la existencia de grupos más cercanos al pueblo como Boedo, esto no significó la exclusión entre unos y otros. En Revista de Oriente se hallaron poemas y cuentos de escritores de este ámbito pero al mismo tiempo se recomendaban textos de Borges e inclusive se reprodujeron algunos fragmentos de sus obras. Por lo que toda expresión artística estaba en función de promover la cultura que aspiraban instalar en el pueblo. Lo cual es claro siguiendo el leit motiv de la publicación, tomado del proletkult: acercar e ilustrar al pueblo a la esfera cultural para elevarlo espiritualmente.

\footnotetext{
${ }^{39}$ Beter, Clara; Revista de Oriente; 1,5 (1925) p. 24.
} 


\section{La posición de Revista de Oriente en el campo cultural: Redes en Buenos Aires y Latinoamérica.}

Una de las definiciones de revista cultural las comprende como punto de encuentro de trayectorias individuales y trayectorias colectivas, esto es evidente en la publicación estudiada, específicamente en la importancia para el enriquecimiento de información y variedad en cada edición. Este elemento no hubiera sido posible sin los contactos de su máximo difusor, Orzábal Quintana, al mismo tiempo que la Asociación de Amigos de Rusia brindó todos aquellos referidos a la cultura soviética.

Arturo Orzábal Quintana desde los primeros años de la década del'20 participó del grupo reformista en el cual identificaba como "maestros" a José Ingenieros y Alfredo Palacios y que en 1925 conformarían la Unión Latinoamericana. Esta agrupación, tuvo su sede en Buenos Aires pero intentó tener filiales en otros países latinoamericanos ya que su principal objetivo era defender al continente del expansionismo imperialista norteamericano. Tomando el concepto de Devés Valdez ${ }^{40}$, una red intelectual, significa los contactos y los intercambios entre especialistas de un área determinada. En este caso se puede pensar que estos contactos e intercambios se dan no solo por especialistas en un área, sino en su interés de encontrar y alcanzar un sistema social alternativo.

A partir de su participación en esta agrupación, que tuvo sus mayores repercusiones fuera de Argentina en México y en Perú, Orzábal Quintana logró establecer vínculos y ser reconocido entre distintos intelectuales de América Latina que luego tuvieron su espacio en Revista de Oriente. Gracias a esto es posible entender las colaboraciones de Mariátegui ${ }^{41}$, de Haya de la Torre ${ }^{42}$ o la entrevista a Diego Rivera ${ }^{43}$. Esta es una de las claves que permite explicar cómo la trayectoria individual de Orzábal Quintana fue crucial para el desarrollo y la heterogeneidad sostenida durante el funcionamiento de Revista de Oriente. El estudio de los intelectuales debe ser entendido no solo como "momentos de su pensamiento", sino como el resultado de un itinerario biográfico que se enriquece a medida que experimentan nuevos proyectos y actividades.

Los artículos que enviaron estos intelectuales constaron esencialmente de reseñas bibliográficas y biográficas como el caso de José Mariátegui acerca de Alejandro Blok, escritor ruso, y de Barbusse. $\mathrm{O}$ en el caso de las palabras de Haya de la Torre, en reconocimiento de la actividad tanto de Revista de Oriente como de la Asociación de Amigos de Rusia:

\footnotetext{
${ }^{40}$ Devés Valdez, Eduardo, Redes intelectuales en América Latina. Hacia la constitución de una comunidad intelectual; (Santiago de Chile: Instituto de Estudios Avanzados Universidad Santiago de Chile, 2007)

${ }^{41}$ José Mariátegui; "El nuevo libro de Henri Barbusse"; Revista de Oriente, 1,2, (1925), p. 25. "Alejandro Blok"; Revista de Oriente, 2,6 (1926).p.21.

${ }^{42}$ Víctor Raúl Haya de la Torre; "Para la Revista de Oriente"; Revista de Oriente; 1,4 (1925), p.7. "Haya de la Torre opina sobre Lunatcharsky"; Revista de Oriente, 1,5, (1925) p. 5

${ }^{43}$ Esteban Pavletich; "Con Diego Rivera. El artista de una clase”; Revista de Oriente 2,9 -10, (1926), p. 10-11
} 
No creo incurrir en el error al afirmar que una publicación como Revista de Oriente hacia falta en América. Por su orientación ideológica, pienso que será una tribuna más- muy importante sin duda-, para nuestro movimiento renovador que después de largos años de tanteos líricos muchas veces inútiles -“enfermedades de la infancia”, quizá- va encauzándose hacia la unidad y la realidad. ${ }^{44}$

En estas líneas, Haya de la Torre otorgó legitimidad a la Revista de Oriente para llevar adelante su tarea de defender los intereses latinoamericanos y la difusión de la realidad soviética. Los textos publicados de estos dos escritores cumplieron la misma función (aunque el de Mariátegui no abordó el tema del proyecto editorial) es decir cargaron con capital simbólico a una publicación con grandes ambiciones pero a la cual le costó encontrar un público capaz de sostenerla a través de los meses.

Otros de los factores pudieron ser la cantidad de revistas similares de la época que generó un clima de competencia por un público "fiel" a una sola de ellas. Como también debe indicarse las enemistades que en su trayectoria fue acumulando Orzábal Quintana, por ejemplo con un sector del Partido Comunista o con el socialista Alfredo Palacios y la ULA, la cual contaba con la participación de parte del estudiantado universitario argentino.

Los vínculos con la intelectualidad peruana también estuvieron presentes a través de las colaboraciones realizadas por algunos universitarios peruanos exiliados por el gobierno de Leguía. Por ejemplo, Oscar Herrera quien aportó un extenso ensayo en el cual denunciaba la falta libertad en su país de origen. La denuncia de este tipo de regímenes aparecía en todos los números al igual que la solicitud de ayuda económica para los estudiantes de las distintas partes del mundo que así la precisaran. Esto fue el resultado de los contactos de Orzábal Quintana y su participación en grupos de jóvenes reformistas que consideraban que la juventud era la encargada de llevar adelante la transformación social.

$\mathrm{Al}$ igual que estas colaboraciones, también aparecieron dos figuras relevantes de la cultura rusa: Anatole Lunatcharsky, el ya referido Comisario de Instrucción Pública, y Nadezha Krúpskaya, esposa de Lenin y educadora rusa. Lunatcharsky envió una carta reconociendo a la Asociación de Amigos de Rusia y la tarea que realizó en el país para la publicitación de la realidad soviética. Mientras que de Krúpskaya se publicó una crónica en donde ella relataba cómo fue el regreso de Lenin a Rusia para llevar adelante la Revolución. Allí comenta los sufrimientos y dificultades que tuvieron que soportar solo por perseguir su ideal: una mejor sociedad. En toda la nota realizaba una detallada crónica del viaje desde Suiza hasta Rusia, luego de que se enteraran del comienzo de la Revolución. Krúpskaya además, le otorgaba un rol importante al pueblo ruso que comenzó la Revolución y que reconocía en Lenin un jefe. En los últimos párrafos indicaba que los obreros, los soldados, los marineros de la capital, habían venido al encuentro de su jefe.

\footnotetext{
${ }^{44}$ Haya de la Torre, Victor; "Para la Revista de Oriente"; Revista de Oriente, 1, 4, (1925), p. 7.
} 
¿Cómo se habían enterado de su arribo? No lo sé. Alrededor nuestro todo era un mar humano. $^{45}$

Este tipo de artículos, obtenidos gracias a los intercambios y vínculos tanto de Orzábal Quintana como de la Asociación de Amigos de Rusia le otorgaron a la publicación cierta distinción que buscaba posicionar a la misma con cierta exclusividad en tareas de difusión de la realidad soviética. El reconocimiento de uno de los líderes del PC argentino, Victorio Codovilla, son indicios que permiten reflexionar acerca de los contactos con este partido y la colaboración del mismo para la obtención de datos de la Rusia Soviética.

Por lo tanto, las colaboraciones y reproducciones de un heterogéneo grupo de intelectuales y artistas construyeron un proyecto colectivo, retomando la idea de Beigel, con características específicas que lo diferenció de otros. Como la conjugación de artículos de la realidad soviética escritos tanto por autores argentinos como extranjeros, los usos de fotografías e imágenes de los acontecimientos culturales rusos y literatura que reafirmaban la defensa y enaltecimiento de la clase trabajadora.

Por otro lado, en el campo cultural argentino las revistas de tendencias de izquierda tenían unos de sus máximos exponentes en Los Pensadores, la publicación editada por el grupo dirigido por el socialista Antonio Zamora y cercana al grupo de Boedo. Allí como ya se señaló, se reunían escritores y artistas de vanguardias opuesta al grupo Florida que buscaban retratar a la sociedad de la manera más real posible (Ferreira de Cassone; 20042005; 2008-2009). Algunos de los participantes de este grupo tuvieron participación en Revista de Oriente a través de las poesías o las imágenes ofrecidas por algunos de los Artistas del Pueblo, vinculados a Boedo, como Guillermo Facio Hebecquer o Pompeyo Audivert. Entre los escritores colaboraron con Revista de Oriente Alvaro Yunque, Cesar Tiempo y Nicolás Olivari, entre otros.

Este cuadro de intercambios y sociabilidades presentes en el proyecto editorial cristalizaron el modo de permeabilidad que existía en los distintos espacios de la intelectualidad argentina. Cada uno de los grupos se nutrió de los debates que aparecieron y se dieron en otros ámbitos con temáticas similares. De esta manera, además de analizar a Revista de Oriente como una de las aristas de la red entre intelectuales latinoamericanos, se expuso su intervención en Buenos Aires de los años '20 en una red de intelectuales y proyectos de izquierda que si bien no tenían todos los mismos objetivos y prismas para analizar el sistema social, compartían un objetivo superior: alcanzar una sociedad más igualitaria y justa.

No obstante, es necesario plantear que al mismo tiempo que esta característica de la revista la nutre y la diferencia también es probable que haya causado la pérdida de apoyo por algunos sectores socialistas o comunistas. Especialmente debido a las duras críticas que el Partido Comunista realiza hacia el sector "reformista" en estos años.

Además de vincularse con el campo artístico, en las publicaciones de Revista Oriente se visualiza el resultado de las relaciones de Orzábal Quintana con el reformismo universitario de La Plata como de Buenos Aires. Tanto en artículos realizados por Alfredo

\footnotetext{
${ }^{45}$ Krúpskaya; Revista de Oriente. 2,6 (1926) pp. 26-27
} 
Palacios o Gabriel Moreau, más la difusión de conferencias de Carlos Sánchez Viamonte. Es interesante la cantidad de publicidad de revistas universitarias argentinas y latinoamericanas.

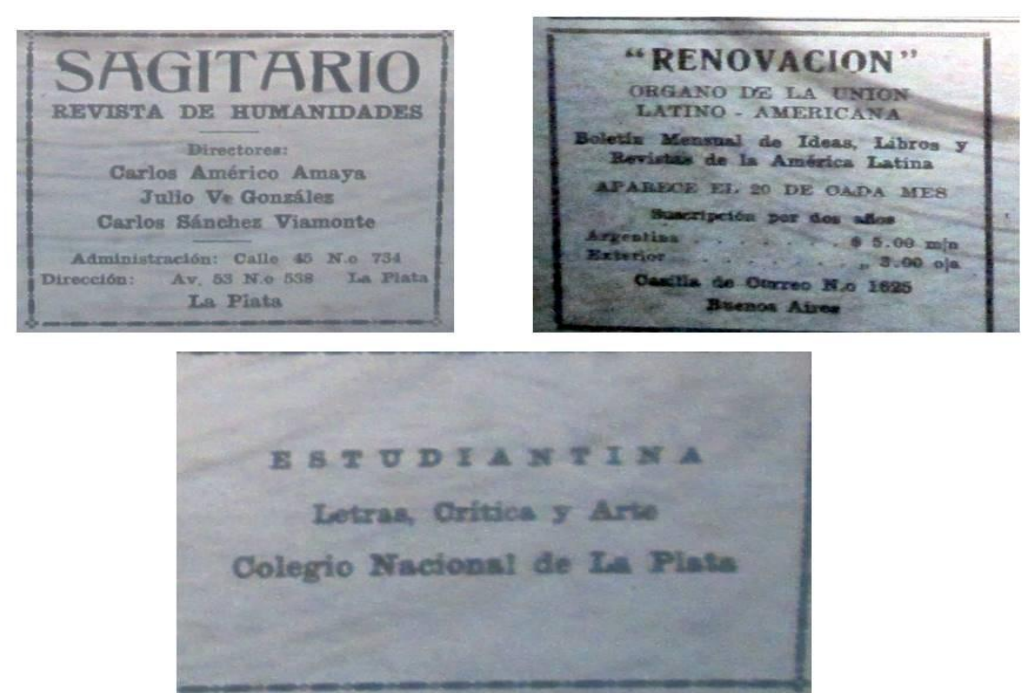

Ilustración 7: Publicidades de Sagitario, Renovación y Estudiantina que aparecían en los números de Revista de Oriente.

Estas publicidades, como se observa en la Ilustración n 7, mostraban uno de los círculos intelectuales en los que intentó captar lectores el proyecto de Revista de Oriente y ser reconocida: el sector estudiantil. De esta manera Revista de Oriente encontró una esfera más para difundir la experiencia soviética y tratar de conseguir el apoyo para lograr el reconocimiento por parte del gobierno argentino. Al igual que denunciar las injusticias de la sociedad burguesa ante un actor potencialmente transformador de toda la sociedad como el estudiantado.

A partir de los vínculos que se señalaron en los párrafos anteriores, la Revista de Oriente se entendió como un proyecto que logró participar y aportar un conocimiento específico de una temática planteada en los debates intelectuales de la década del '20: la Revolución Bolchevique, como sostiene Sarlo al referirse al impacto que esta provocó en los diferentes círculos culturales porteños ${ }^{46}$. Fueron fundamentales los contactos entre esta publicación y otros similares tanto en América Latina como en la esfera cultural de Buenos Aires. Tanto para alcanzar reconocimiento y legitimidad según las normas propias del campo de izquierda como para obtener el apoyo para llegar a los objetivos planteados desde el primer número y la continuidad de la revista.

${ }^{46}$ Sarlo, Beatriz, op. cit. 


\section{Conclusiones}

En el presente trabajo se intentó comprender la intervención de Arturo Orzábal Quintana y de la Revista de Oriente en el campo cultural argentino durante los años 1925 y 1926. Analizándola como una revista formada por intelectuales de izquierda que defendían la revolución rusa e instalaron en el espacio público lo acontecido en la Rusia soviética mediante artículos informativos y el uso de imágenes y relatos literarios.

La Revolución Bolchevique había generado un fuerte impacto en el resto de Europa como en América. Los intelectuales que se alinearon a ella emprendieron proyectos editoriales y dasociaciones que intentaban defender el nuevo sistema instalado en Rusia. En Argentina el propio Partido Comunista tenía sus publicaciones políticas pero también la Editorial Claridad, dirigida por el socialista Antonio Zamora, se encargó de difundir el proyecto sovietista en el país.

En este clima, en junio de 1925 salió el primer número de Revista de Oriente. Fue distribuida principalmente en Buenos Aires pero tuvo alcance en Córdoba, Rosario, La Plata y otros pueblos del interior. El proyecto editorial contó con ocho números, dos de los cuales fueron dobles, ya que por dificultades económicas fue insostenible por un lapso mayor de tiempo.

Esta revista se caracterizó por la variedad tanto de sus artículos como de colaboradores. Por una parte era posible hallar ensayos acerca de la realidad soviética y de política nacional, en menor medida, e internacional. Pero también una interesante cantidad de textos literarios como poesías y cuentos que funcionaron a modo de "enseñanza" acerca de distintas situaciones de la vida cotidiana. Esta característica es señalada por Eujanian y Giordano $^{47}$ en Claridad y definida como "función pedagógica" de la revista de izquierda.

En Revista de Oriente también se pudo hallar esto pero con rasgos distintos, esencialmente esta se encarga de orientar a sus lectores a la defensa de la nueva sociedad rusa mediante el uso de recursos estéticos y literarios. El analisis de este proyecto editorial intentó demostrar que su singularidad radica en los recursos artísticos y su búsqueda de apelar a distintos grupos de lectores para poder difundir las transformaciones del gobierno sovietista.

Revista de Oriente mediante este uso de las imágenes, tanto reproducciones de obras de arte como de fotografías, se distinguió de las publicaciones partidarias y buscó atraer y concientizar un púbico variado en el cual se encontraban, estudiantes, intelectuales y obreros. Al estudiarla resultan interesantes las ilustraciones que se burlan de los grandes hombres burgueses, de políticos y de la policía. Como también las reproducciones de grabados exaltando la figura y la capacidad del obrero o las fotografías acerca de exposiciones rusas, inauguración de monumentos o eventos soviéticos.

Estas características pueden ser entendidas como el resultado de los vínculos e intercambios ocurridos en el campo cultural argentino y latinoamericano durante los años

\footnotetext{
${ }^{47}$ Eujanian, Alejandro y Giordano, Alberto, op. cit.
} 
'20. Como se ha mencionado en el trabajo, la revista cultural fue un punto de encuentro de trayectorias individuales y colectivas. En otras palabras, Revista de Oriente permitió la confluencia de intelectuales, artistas y políticos que tenían un objetivo primordial en común: alcanzar una sociedad alternativa. Este ecléctico grupo no hubiera existido sin las relaciones que cada uno de ellos tejió durante el período en diferentes espacios.

En la revista aparecieron aportes y participación de tres actores fundamentales: intelectuales, artistas y universitarios. Esto fue el resultado, principalmente, de los vínculos de Arturo Orzábal Quintana con cada uno de ellos. Este abogado durante toda la década del veinte realizó una actividad importante en el campo cultural argentino. Su participación en la Unión Latinoamericana, compuesta por jóvenes reformistas y con repercusión en países como México y Perú, le permitió contar con el apoyo de algunos de estos y con el reconocimiento de Mariátegui y Haya de la Torre al momento de embarcarse en la tarea de Revista de Oriente.

Por otra parte, su relevancia como difusor de ideas de izquierda le facilitó el acercamiento a los grupos artísticos de vanguardia que también denunciaban las injusticias del sistema capitalista a través de relatos u obras plásticas, como Álvaro Yunque o José Planas Casas. Al igual que sus actividades como conferencista en las universidades de La Plata y de Buenos Aires. Mientras que la Asociación de Amigos de Rusia estaba respaldada por el gobierno soviético, específicamente el Comisario de Instrucción Pública Anatole Lunatcharsky.

Por lo tanto, la Revista de Oriente se constituyó como parte una red intelectual, a través de los intercambios entre especialistas del tema, como lo propone Devés Valdez ${ }^{48}$. Las reciprocas notas y cartas entre las organizaciones latinoamericanas y argentinas fueron evidentes en todos los números ya sea por reproducción de las mismas como por las publicidades que aparecieron de otros proyectos editoriales. Además como eslabón de una red también a nivel nacional, entre los distintos espacios políticos, artísticos e intelectuales que participaron en el apoyo la propaganda y difusión del régimen soviético. Por lo tanto, la variedad de los artículos publicados se debió a este tipo de vínculos construidos en un campo político y cultural específico.

Revista de Oriente publicó cuentos y poesías que pretendían modificar el régimen capitalista o al menos, hacer reflexionar al trabajador acerca de la opresión de la cual eran víctimas. Además el número de ilustraciones permitían una lectura de la publicación que no solo constaba de la descripción de los avances económicos y políticos de la Rusia Soviética, sino que además atraía mediante la narración de las injusticias cotidianas, sufridas tanto en la Rusia zarista como en cualquier país en donde dominara el capitalismo. Por este motivo, se sostiene que el arte y su divulgación fue comprendido por el grupo editorial como una de las vías necesarias para transformar el régimen capitalista. El uso de imágenes, reproducciones de obras de arte, fotografías y poesías y cuentos para representar la realidad soviética y latinoamericana fue un elemento sustancial en Revista de Oriente. De

\footnotetext{
${ }^{48}$ Deves Valdez, Eduardo, op. cit.
} 
este modo, como se ha visto, los recursos artísticos fueron la herramienta que les permitió diferenciar su acercamiento a sus lectores, principalmente a los obreros.

El estudio de este proyecto permitió comprender la relevancia tanto de los actores individuales, al momento de impulsar una iniciativa singular y contar con un sustento que lo respalde, como también de actores colectivos que otorguen el apoyo como organización en un campo cultural en el cual se definieron los propios modos de reconocimiento y legitimación.

Recibido: 4 marzo 2015
Aceptado: 7 agosto 2015

\section{Obras Citadas}

Artundo Patricia, "Las revistas como objeto de estudio"; en Saavedra Patricia y Artundo Patricia (dir.), Leer las artes. Las artes plásticas en ocho revistas culturales argentinas (1878-1951), (Buenos Aires: Facultad de Filosofía y Letras UBA, (2002).

Baur, Sergio, "Itinerario de la vanguardia argentina", Dirasat Hispanicas 1, (2014).

Beigel, Fernanda, "Las revistas culturales como documentos de la historia latinoamericana"; Utopía y Praxis Latinoamericana 8, 20 (2003) pp. 105-105.

Bergel; Martin, "Un caso de orientalismo invertido. La revista Oriente (1925-1926) y los modelos de relevo de la civilización occidental", Prismas 10 (2006)

Buchbinder, Pablo, Historia de la Universidades Argentinas (Buenos Aires: Sudamericana 2010)

Camarero Hernán, "La experiencia comunista en el mundo de los trabajadores, 1925-1935", Prismas. Revista de Historia Intelectual 6 (2002)

Colombi, Beatriz, Viaje intelectual. Migraciones y desplazamientos en América Latina (18801915), (Rosario, Beatriz Viterbo Editora; 2004).

De Micheli, Mario, Las vanguardias artísticas del siglo XX, (Madrid: Alianza Editorial; 1994)

Delgado, Veronica, El nacimiento de la literatura argentina en las revistas literarias (1896-1913), (La Plata, Universidad Nacional de La Plata; 2009).

Devés Valdéz, Eduardo, Redes intelectuales en América Latina. Hacia la constitución de una comunidad intelectual,(Santiago de Chile: Instituto de Estudios Avanzados Universidad Santiago de Chile; 2007).

Dolinko, Silvia, "De la revisión del artista del pueblo al cuestionamiento institucional. Lecturas sobre Guillermo Facio Hebequer”, A Contracorriente 8, 2 (2011).

Eujanian, Alejandro, Historia de las revistas argentinas 1900-1950 (Buenos Aires: Asociación de Editores de Revistas, 1999) 
Eujanian, Alejandro, Giordano, Alberto, "Las revistas de izquierda y la función de la literatura: Enseñanza y propaganda", en Gramuglio, M. Teresa, Historia crítica de la literatura argentina. Vol. 6: El imperio realista. Colección dirigida por Noe Jitrik;(Buenos Aires: Emecé editores, 2002) Ferreira de Cassone, Florencia, "Socialismo y literatura en la Argentina. Una experiencia editorial", Cuyo. Anuario de Filosofía Argentina y Americana, 21/22 (2004-2005).

Ferreira de Cassone, Florencia, "Boedo y Florida en las páginas de los pensadores". Cuyo Anuario de Filosofía Argentina y Americana, 25/26, (2008-2009)

Graciano, Osvaldo, Entre la torre de marfil y el compromiso político. Intelectuales de izquierda en Argentina, 1918 - 1955, (Bernal: Editorial de la Universidad Nacional de Quilmes, 2008)

Gramuglio, M. Teresa, "Introducción” y "El realismo y sus destiempos en la literatura argentina" en Historia Crítica de la literatura argentina. Vol. 6: El imperio realista. Colección dirigida por Noe Jitrik,(Buenos Aires: Emecé editores; Buenos Aires, 2002).

Lobato, Mirta, La prensa obrera: Buenos Aires y Montevideo, 1890-1958, (Buenos Aires: Edhasa, 2009)

Lopez Amaya, Jorge, Historia del arte argentino, (Buenos Aires: Emecé editores, 1997)

Losada, Leandro, Historia de las elites en la Argentina. Desde la conquista hasta el surgimiento del peronismo, (Buenos Aires: Sudamericana, 2009)

Mally; Lynn, Culture of the future: The proletkult movement in revolutionary Russia; (Berkeley: University California Press, 1990).

Montaldo Graciela, "La literatura como pedagogía, el escritor como modelo", Cuadernos Hispanoamericanos, 445 (1987), pp.40-64.

Pita González, Alexandra, La Unión Latinoamericana y el Boletín Renovación Redes intelectuales y revistas culturales en la década del '20 (México: El Colegio de México/Universidad de Colima, 2009)

Rock, David, El radicalismo argentino. 1890-1930, (Buenos Aires: Amorrortu Editores, 1992)

Sarlo Beatriz, Una modernidad periférica. Buenos Aires 1920-1930, (Buenos Aires: Nueva Visión, 2003)

Terán, Oscar, Ideas en el siglo. Intelectuales y cultura en el siglo XX latinoamericano, (Buenos Aires: Siglo XXI Editores, 2004)

Tarcus, Horacio, Diccionario biográfico de la izquierda argentina de los anarquistas a la "nueva izquierda", 1870-1976(Buenos Aires: Emece, 2007)

Tarcus, Horacio, "Revistas, intelectuales y formaciones culturales izquierdistas en la Argentina de los veinte" Revista Iberoamericana, 70,208-209 (2004) 